\title{
Extractive/oxidative desulfurization optimization of diesel feed stock by ionic liquid utilization/thermodynamic analysis
}

\author{
Qasim Y. Rahawi*, Nadjet Berrabia**, Boudjema Hamada** and Ahmed M. Daabo*, **** \\ * University of Mosul, College of Petroleum and Mining Engineering, Mosul, Iraq \\ ** University of M'hamed Bougara Boumerdes, Petrochemical Synthesis Laboratory, Boumerdes, Algeria \\ ***ahmeddaboo@yahoo.com
}

$\begin{array}{ll}\text { Submitted } & : 14 / 10 / 2020 \\ \text { Revised } & : 11 / 05 / 2021 \\ \text { Accepted } & : 22 / 05 / 2021\end{array}$

\begin{abstract}
The current research paper focuses on the physicochemical optimization's parameters for the Microwave Assisted Extractive/Oxidative Desulfurization (MAEOD) of a real Algerian diesel. The oxidative desulfurization was carried out using vanadyl acetyl acetonate as catalyst, hydrogen peroxide (30\%) as oxidant, and an acid Bronsted Ionic Liquid (IL) in situ synthesized as extractor. The utilized optimization method is consistent with the full factorial experiment. The engaged parameters are the masse ratio (catalyst/oil), the volume ratio (IL/oil), and the reaction time. Quantification of total sulfur in samples was realized by X-ray fluorescence, and a regression model is formed. The most important model parameters' interaction effects are examined, and the ISO-response curves are outlined in order to simulate the optimal conditions. The optimum yield (81.77\%) was achieved during a time radiation of $70 \mathrm{~s}$ with a catalyst/oil ratio of $0.4 \%$ and IL/oil volume ratio of $11 \%$, with correlation 99.21 .
\end{abstract}

Keywords: Optimization; Oxidative desulfurization; Microwaves; Ionic liquid.

\section{INTRODUCTION}

Limiting sulfur content to ultralow levels has recently been one of the most important fuel regulations with the goal of decreasing the environmental and health consequences because of the acid rains and the air pollution associated with the transportation fuels' combustion, which forms SOx. It is looking ahead to have zero-emission in the forthcoming future based on (Aguiar et al., 2014 \& Moussa et al., 2014) as a result of the increased attention, which has been directed toward efficient and novel desulfurization technologies (Su et al. 2019).

Recently, there has been a better interest in examining some alternate energy sources in the transportation and energy sectors (Afzal et al., 2019).

As it can be accomplished without the need for Hydrogen and also at low pressure and temperature values, Oxidative Desulfurization (ODS) is considered a better approach than Hydrogen Desulfurization (HDS) and, as a result, one of the encouraging technologies (Meman et al., 2014). 
In ODS approach, the temperature value should be under a sensitive control, and as this is reachable with using microwave energy, this can be one of the key reasons for spreading this approach and getting the researchers' attention. This energy has a frequency ranging from $0.3 \mathrm{GHz}$ to $300 \mathrm{GHz}$, with electromagnetic spectrum being between radiofrequency and infrared radiation and wavelengths between $1 \mathrm{~mm}$ and $1 \mathrm{~m}$ (Ma et al., 2014). Some effective methods of nitrogen and sulfur compounds removal, using ILs from real and model fuels, were presented by a study done by Zolotareva et al. (2019). A review study about "Ionic Liquids for Desulphurization" was recently carried out by S. Abdullah et al. (2018). It concluded that further research is needed in the field of extractive desulphurization process using selective ILs.

Because of their attractive chemical and physical properties, that is, no flammability, thermal and chemical stability, and low vapor pressures, Ionic Liquids (ILs) have recently attracted the scientific community's attention. The latter is considered a stellar option to substitute volatile organic solvents for extra clean and green technologies (Nie et al., 2013; Martinez-Magadan et al., 2012). It is well known that the ILs can not remove a high amount of sulfur with the absence of oxidant. Nevertheless, high oxidant/sulfur rations should be applied for sulfur removal if there is no catalyst. Many types of the latter, which are able to remove high sulfur at low oxidant/sulfur ratios, molybdenum, and iron catalysts, have been examined by Mota et al. (2012), Zhu et al. (2011), Lü et al. (2014), and Jiang et al. (2014), respectively. A prepared functional "[Bmim $] \mathrm{Cl} / \mathrm{CoCl}_{2}$ ionic liquid" with potassium monopersulfate (PMS) was prepared to eliminate benzothiophene from octane. [Bmim] $\mathrm{Cl} / \mathrm{CoCl}_{2}, \mathrm{PMS}$ dosage, reaction time, and temperature for desulfurization were examined based on response surface methodology and real experiment. The order of four experimental conditions followed the temperature $>$ time $>[\mathrm{Bmim}] \mathrm{Cl} / \mathrm{CoCl}_{2}$ dosage > PMS solution dosage (Y. Zhang et al., 2018).

The overall objective of this project work is to investigate the use of nonconventional, other than Hydrodesulfurization (HDS) process, chemical methods for the desulfurization of fuel oils. In general, the chemical methods should be more selective, inexpensive, efficient, and regenerable to justify further development of work. These methods will include chemical oxidation, solvent extraction, adsorption, and the use of a novel laser-based photo-oxidation process. The authors, here, report a simple procedure for desulfurization of model fuel oil by chemical oxidation and extraction with ionic liquids. So, the principal idea behind the current research is to examine the optimum circumstances to reach a maximum desulfurization level of real diesel feedstock using a combination of microwave radiations and catalytic activity of $\left(\mathrm{VO}(\mathrm{acac})_{2}\right)$ in an acid Bronsted ionic liquid, synthesized under microwave radiations.

\section{MATERIALS AND METHODS}

\subsection{Materials}

Vanadyl acetylacetonate ( $\left.\mathrm{VO}(\mathrm{acac})_{2}\right)$ catalyst was synthesized with respect to a method reported by Woolins et al. (2014) and purified by recrystallization from $\mathrm{CHCl}_{3}$ (Gekhman et al., 1998). Real diesel fuel with a total S-content of $450 \mathrm{ppm}$ is supplied by Algiers Refinery. Chemicals were purchased from different companies and used as received. Chloroacetic acid, hydrogen peroxide, and pyridine (30 \%, v/v) were delivered from "Sigma Aldrich." All solvents, $\mathrm{CaCl}_{2}$, and sulfuric acid were purchased from "Panreac Company."

\subsection{IL synthesis and characterization}

The acid Bronsted ionic liquid [CH2COOHPy] [HSO4] was made regarding the "two-step synthesis method." At the start, $1.2 \mathrm{~mol}$ of Pyridine and $1.0 \mathrm{~mol}$ of Chloroacetic Acid were placed in a refluxed round bottom flask and mixed in a magnetic stirrer, and the mixture is heated intermittently in a perforated household MW oven (Brandt SE2612S-900W) at $150 \mathrm{~W}$ (1 min irradiation with $10 \mathrm{~min}$ mixing) until a white precipitate is formed. 
In order to get $\left[\mathrm{CH}_{2} \mathrm{COOHPy}\right] \mathrm{Cl}$, which then was dried using vacuum, the precipitate was firstly filtered off and then washed with dichloromethane three times.

After that:

1- A "3-neck refluxed round" bottom flask is used.

2- Equimolar quantities of "Sulfuric acid" (96\%) were dropped, gradually, to $\left[\mathrm{CH}_{2} \mathrm{COOHPy}\right] \mathrm{Cl}$ at the same conditions of the microwaves to obtain $\left[\mathrm{CH}_{2} \mathrm{COOHPy}\right]\left[\mathrm{HSO}_{4}\right]$.

3- Sodium hydroxide solution was then used to absorb the by-product $\mathrm{HCl}$.

4- Once the generated $\mathrm{HCl}$ was not sensed by Ammonia solution, the $\left[\mathrm{CH}_{2} \mathrm{COOHPy}\right]\left[\mathrm{HSO}_{4}\right]$ needed to be dried at vacuum, and we used a desiccator to store it.

The structure of IL has been identified by ${ }^{1} \mathrm{H}$ NMR and ${ }^{13} \mathrm{C}$ NMR (Bruker $300 \mathrm{MHz}$ ) and infrared spectra (Bruker Alpha-T). The density of IL was determined by "Pycnometer method," and "Rotational Rheometer (RS600, Thermo, USA)" was operated to find out its viscosity, where the results were as follows:

“Density: $1.75 \mathrm{~g} / \mathrm{ml}\left(30^{\circ} \mathrm{C}\right)$; viscosity: 0.30 Pas $\left(30^{\circ} \mathrm{C}\right)$.), infrared spectrum $\left(\mathrm{KBr}, \gamma / \mathrm{cm}^{-1}\right): 3396,2924,1735$, 1638, 1490, 1229, 1063, 839, 585, 641, 455. ${ }^{1} \mathrm{H}$ NMR (300 MHz, D2O): 5.21 (s, 2H), 7.79(t, 2H), 8.30 (t, 1H), 8.49 (d, 2H); ${ }^{13 \mathrm{C}} \mathrm{NMR}\left(300 \mathrm{MHz}, \mathrm{D}_{2} \mathrm{O}\right): 58.66,126.22,143.64,145.04,166.13 . ”$

\subsection{Extraction-Oxidation Desulfurization}

The experiments of MAEODS were carried out using a $50 \mathrm{~mL}$ of a "round-bottom flask." The $1.2 \mathrm{~mL}$ of ionic liquid, $20 \mathrm{~mL}$ of model oil, 40mg of $\mathrm{VO}(\mathrm{acac})_{2}$, and $\mathrm{H}_{2} \mathrm{O}_{2}$ mixture was stirred vigorously under $\mathrm{MW}$ conditions for $3.5 \mathrm{~min}$ as shown in Figure 1. Two layers formed. The upper oil phase was separated, washed, dried, and analyzed. The lower IL/catalyst phase was reused without regeneration.

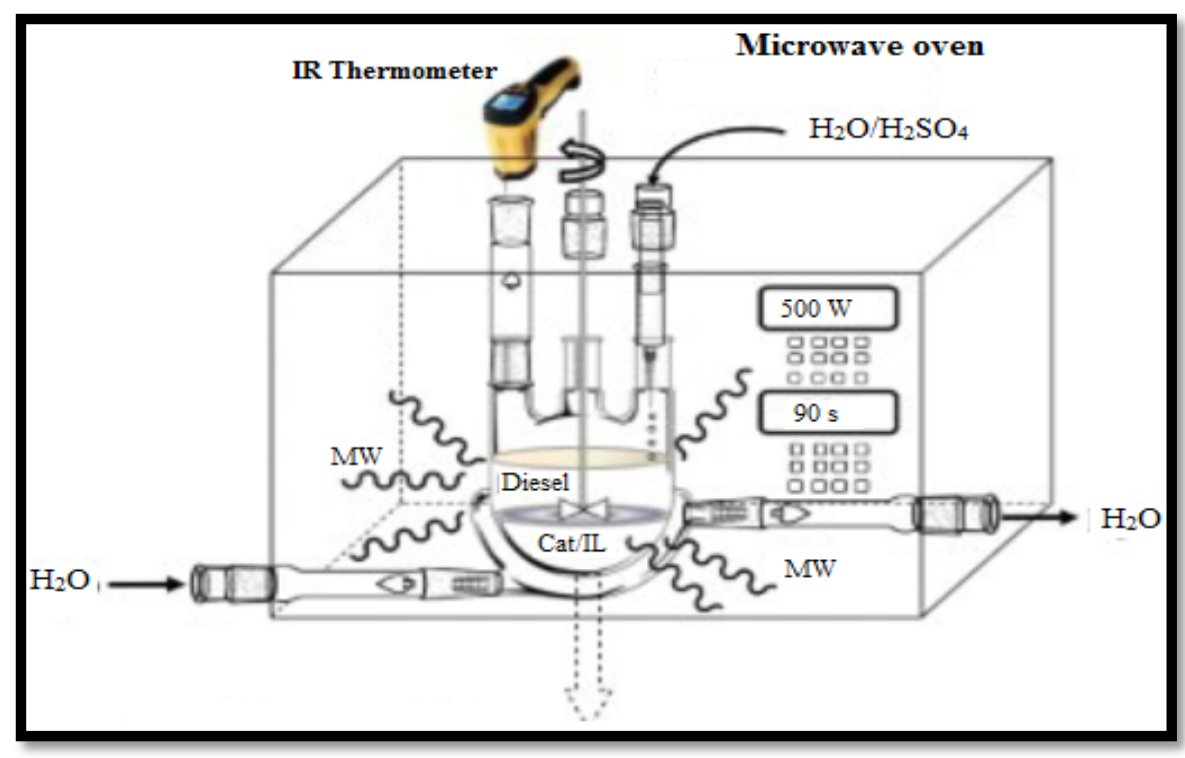

Figure 1. The experimental setting. 
The "desulfurization yield ( $\mathrm{R} \%)$ " is computed using equation (1):

$$
R \%=\frac{C_{0}-C_{t}}{C_{0}} \times 100
$$

where $\mathrm{C}_{0}$ and $\mathrm{C}_{\mathrm{t}}$ represent the initial and at time (t) (after treatment) sulfur concentration (ppm), respectively.

\subsection{Sulfur analysis}

The total concentration of sulfur in diesel samples was analyzed by X-ray fluorescence using un "X-ray fluorescence spectrometer (OXFORD Lab X-3500)" according to the standard method (ASTM 2622). Using what is known as "six liquid calibration standards (obtained from AccuStandard)" and at a range from 0 to $1000 \mathrm{ppm}$ concentration ratio, the spectrometer calibration was carried out.

\subsection{Design of experiments}

Understanding the procedure of optimization in depth can lay the groundwork for correct and suitable optimization with lower possible cost (Daabo et al., 2018-2020). The term "fitness" in nature can be characterized as the most robust strategy. From this point, the idea of optimized Extractive/Oxidative Desulfurization began and is presented in this paper. With the aim of optimizing the related parameters as well as analyzing their interaction, a complete "factorial design" was operated in this research. The latter is a "first-degree polynomial mathematical model" and a "statistical technique." It is beneficial and suitable for "modeling and analyzing the problems," in which their "response of interest" is affected by a number of variables (Montgomery, 2001). These variables are as follows:

1- "Volume reaction (IL/oil)", $\mathrm{X}_{1}$.

2- "Masse ratio (catalyst/oil)", $\mathrm{X}_{2}$.

3- "Reaction time", $\mathrm{X}_{3}$.

The above parameters as well as their upper and lower values, that is, ranges, were selected based on the preliminary experiments and literature data and. The mathematical model of the experimental results is given as follows:

$$
Y=a_{0}+\sum_{i=1}^{n} a_{i} X_{i}+\sum_{i=1}^{n-1} \sum_{j=i+1}^{n} a_{i j} X_{i} X_{j}+\sum_{i=1}^{n-2} \sum_{j=i+1}^{n-1} \sum_{k=j+1}^{n} a_{i j k} X_{i} X_{i} X_{k}+\sum_{i=1}^{n-3} \sum_{j=i+1}^{n} \sum_{k=j+1}^{n-1} \sum_{l=k+1}^{n} q_{i j k l} X_{i} X_{j} X_{k} X_{l}
$$

where the predicted response (desulfurization yield) is represented by $\mathrm{Y}, \mathrm{a}_{0}, \mathrm{a}_{\mathrm{i}} \mathrm{a}_{\mathrm{i}-1}$, are the constant coefficient, the linear coefficients, and the interaction coefficients, respectively. Similarly, $X_{\mathrm{i}}, \mathrm{X}_{\mathrm{j}}, \mathrm{X}_{\mathrm{k}}$ and $\mathrm{X}_{\mathrm{l}}$ are the "coded values" of the desulfurization conditions variables. 


\section{RESULTS AND DISCUSSIONS}

\subsection{Optimum Conditions}

Using the "full factorial experiment" at two various levels, where the lower level was coded with value of $(-1)$ and the upper one with (+1), the current analysis has been carried on, as given in Table 1 .

Table 1. Conditions of experimental design.

\begin{tabular}{|c|c|c|c|}
\hline Parameters & Designation & Level (-) & Level (+) \\
\hline Volume ratio IL/oil (\%) & $\mathrm{X}_{1}$ & 9 & 11 \\
\hline Masse ratio catalyst/oil (\%) & $\mathrm{X}_{2}$ & 0.4 & 0.6 \\
\hline Reaction time (s) & $\mathrm{X}_{3}$ & 70 & 110 \\
\hline
\end{tabular}

\subsection{Planning of Desulfurization Reactions}

As is clear, eight reactions can be achieved using four parameters for any "experimental design." The latter has been carried out based on the "Matrix of Experience" shown in Table 2 that uses three parameters under investigations, mentioned earlier. So, $23(=8)$ will result in reactions and requires the realization of 8 desulfurization reactions. The results of desulfurization are given in the last column.

Table 2. Experimental design matrix for diesel oxidative desulfurization.

\begin{tabular}{|c|c|c|c|c|}
\hline Test $\mathrm{n}^{\circ}$ & $\mathrm{X} 1(\mathrm{v}, \%)$ & $\mathrm{X} 2(\mathrm{wt}, \%)$ & $\mathrm{X} 3(\mathrm{t})$ & Desulfurization yield (\%) \\
\hline 1 & -1 & -1 & -1 & 71.54 \\
\hline 2 & +1 & -1 & -1 & 71.77 \\
\hline 3 & -1 & +1 & -1 & 74.12 \\
\hline 4 & +1 & +1 & -1 & 77.46 \\
\hline 5 & -1 & -1 & +1 & 75.90 \\
\hline 6 & +1 & -1 & +1 & 79.12 \\
\hline 7 & -1 & +1 & +1 & 78.79 \\
\hline 8 & +1 & +1 & +1 & 75.90 \\
\hline
\end{tabular}




\subsection{Development of Regression Model}

Based on Yates method (Atikler et al., 1997), which results in model that has eight unknown variables and equations, the current work has been carried out with the aim of finding out the effect of both the main variables and their interactions. The mentioned model is given using the "Matrix product" where the relevant data were statistically preserved using the software "MODDE 6.0." Equation (3) shows its mathematical model:

$$
Y=76.9373+1.64125 X_{1}-0.161249 X_{2}+0.69875 X_{3}-1.52876 X_{1} X_{2}-1.55875 X_{1} X_{3}+0.0787482 X_{2} X_{3}
$$

Using the "Ascendant regression method, forward technique" (Boehm et al., 1994), the influence of each individual parameter has been figured out. The highlighted technique results in "submodels," in which different criteria can be utilized to govern their choice. It is well known that the value of "the correlation coefficient $\left(\mathrm{R}^{2}\right)$ " can be one of the most important methods that can evaluate the suitability degree (Gürses et al., 2002). Having said that, the value of "the correlation coefficient $\left(\mathrm{R}^{2}\right)$ " can be increased monotonically when new variables are introduced, that is, less or more correlated with respect to the old ones. So, to solve this issue, "the higher adjusted $\mathrm{R}^{2}$ adj value" was selected.

The "parameter significance level" was set to $p=0.05$, where the outcome of programmed "tests model" is given in Table 3, which shows that the highest influence parameter, with a 0.000366019 probability, was the volume ratio $(\mathrm{LI} /$ oil $)\left(\mathrm{X}_{1}\right)$.

Table 3. The influence of the selected parameters and their interactions.

\begin{tabular}{|c|c|c|}
\hline \multicolumn{2}{|c|}{ Model } \\
\hline $\mathrm{Y}$ & Coeff & $\mathrm{P}$ \\
\hline Constant & 76.9373 & $8.41282 .10^{-13}$ \\
\hline $\mathrm{X}_{1}$ & 1.64125 & 0.000366019 \\
\hline $\mathrm{X}_{2}$ & -0.161249 & 0.440601 \\
\hline $\mathrm{X}_{3}$ & 0.69875 & 0.0150875 \\
\hline $\mathrm{X}_{1} * \mathrm{X}_{2}$ & -1.52876 & 0.000511185 \\
\hline $\mathrm{X}_{1} * \mathrm{X}_{3}$ & -1.55875 & 0.000466655 \\
\hline
\end{tabular}

As seen in Table 3, the masse ratio (catalyst/oil) is not an influent parameter for the MAEODS ( $\mathrm{P}=0.440601)$. As the standards of choice of "influent parameters" should not be only mathematical, this parameter has been maintained. The best "statistical indicators" of the model parameters are shown in Table 4, while the general equation, that is, equation 3 , becomes 
Table 4. Adsorption yield of variances (ANOVA).

\begin{tabular}{|c|c|c|c|c|c|c|}
\hline Desulfurization yield (Y) & D1 & SS & Variance (MS) & F & P & SD \\
\hline Total & 11 & 65178.1 & 5925.28 & & & \\
\hline $\begin{array}{c}\text { Constant } \\
\text { of corrected average } \\
\left(Y_{i}-\bar{Y}\right)\end{array}$ & 10 & 65.2813 & 6.52812 & & & \\
\hline $\begin{array}{c}\text { Corrected model of the } \\
\text { average }\end{array}$ & 5 & 63.7977 & 12.7595 & 43.0036 & 0.00 & 3.57205 \\
\hline$\left.Y_{i}^{\prime}-\bar{Y}\right)$ & 5 & 1.48354 & 0.296708 & & & \\
\hline \begin{tabular}{c} 
Residues \\
\hline
\end{tabular} & & & & & & \\
\hline
\end{tabular}

By completing the modeling, variance analysis (ANOVA) contributes to obtaining more data about the investigated parameters (Goupy et al., 2006), where both pertinence verification and postulated model quality evaluation were the main concern of this step. Similar to the previous table, Table 5 presented the results obtained about the "parameters and their interactions on the adsorption yield." The achieved results of $\mathrm{R}^{2}, \mathrm{R}^{2}$ adj, the predictive ability given the coefficient $\mathrm{Q}^{2}$, and the probability $\mathrm{P}$, that is, $0.979,0.958,0.888$, and close to 0 , respectively, indicated the ability of the statistical tests used in the variances analysis to verify the model. After modeling, the "analysis of the residues" (Goupy et al., 2006) was utilized in order to obtain the information included in the responses. Therefore, the way that residues were dispersed, with respect to the "responses predicted by the model," can be figured out.

Based on Figure 2, the computed desulfurization values were distributed in a way that does not give a clear tendency to those points. So, the mentioned information was considered not that important for those specific data, and the model was considered appropriate.

The relative importance of different "significant parameters" is presented in Figure 3. The main outcome from this figure was that it highlighted that, compared to other parameters, $\mathrm{X}_{2}$ is the only one that has "negative effect on the desulfurization reaction."

Figure 4 indicates a considerable interaction concerning $\mathrm{X}_{1}$ and $\mathrm{X}_{3}$, while $\mathrm{X}_{1}$ is kept at its extreme levels (-1) or $(+1)$, and the desulfurization yield decreases or increases, respectively.

The desulfurization variation highlights that when $\mathrm{X}_{1}$ is preserved at its low level, it rises with increasing $\mathrm{X}_{3}$, but when $X_{1}$ is maintained at its high level, it decreases with rising $X_{3}$, so when $X_{1}$ is kept at its high level $(+1)$, and $\mathrm{X}_{3}$ is kept at its low point, the yield is better. 


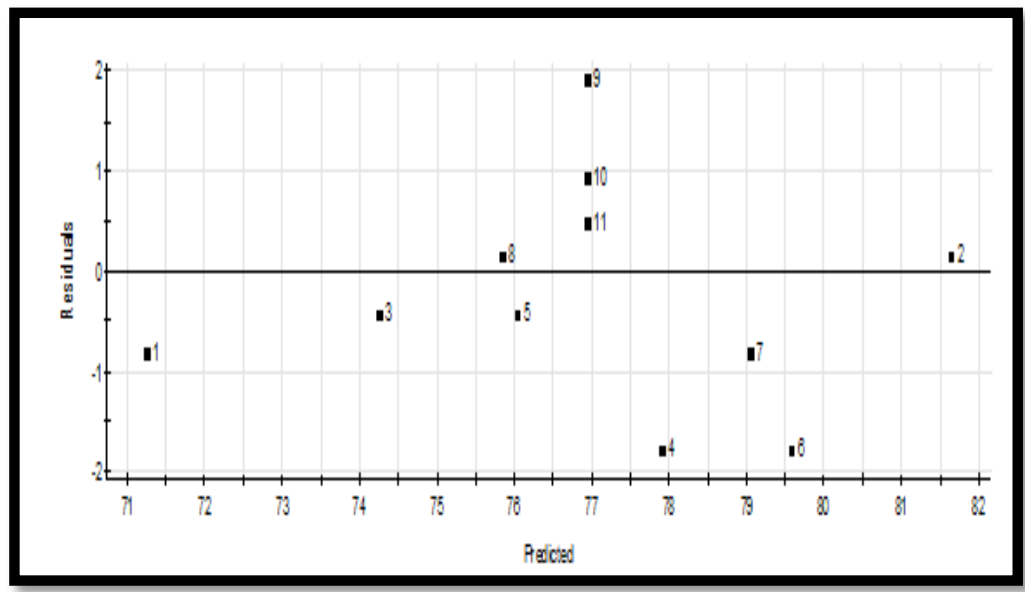

Figure 2. Response residuals achieved by the current study.

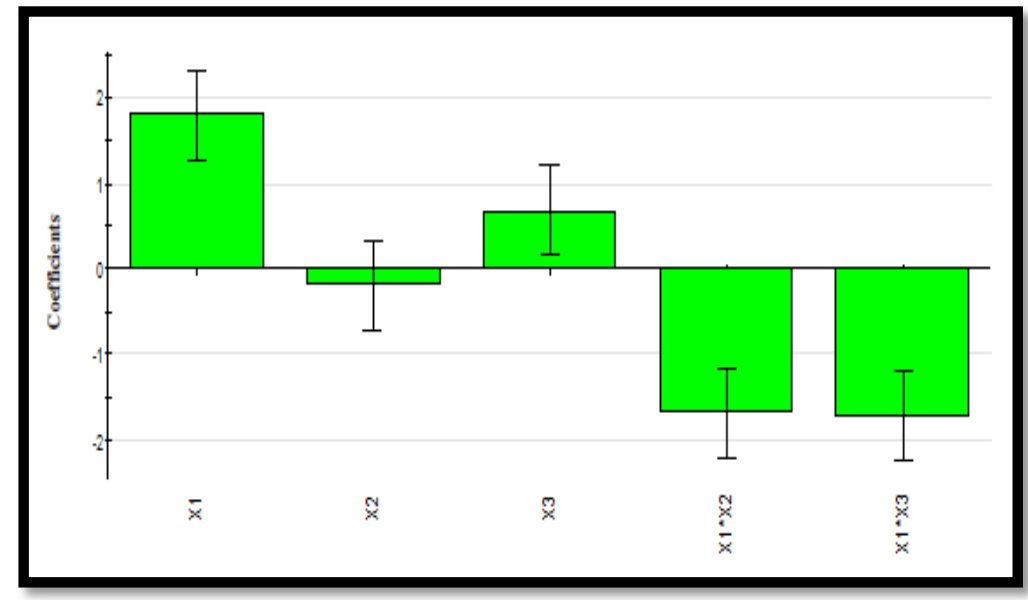

Figure 3. The influence of both the parameters and the interactions of the simplified model.

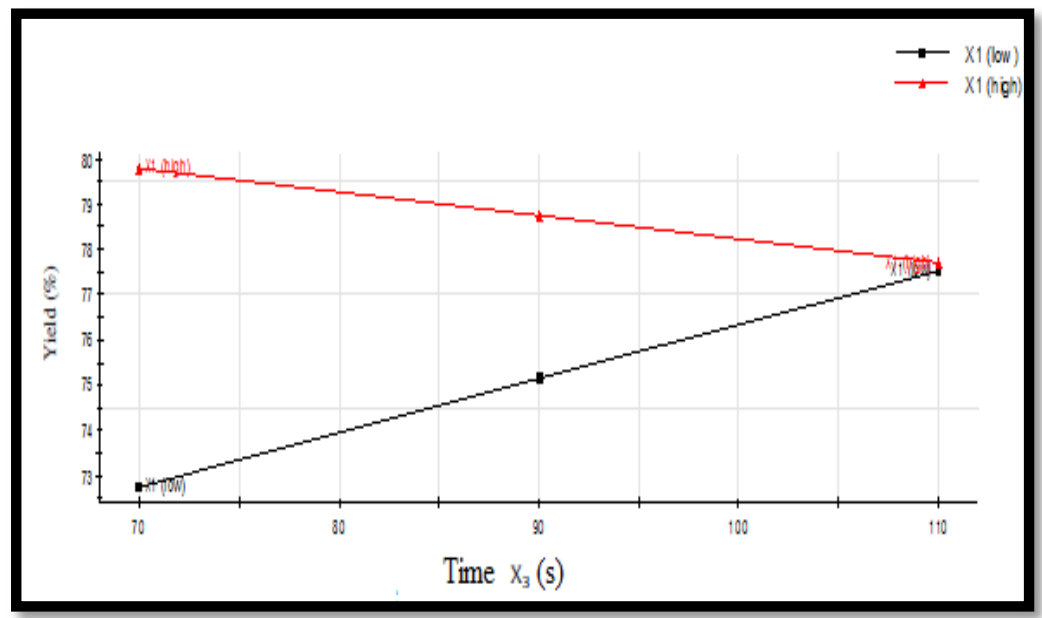

Figure 4. The influence of interaction $\mathrm{X} 1 * \mathrm{X} 3$. 


\subsection{Investigation of the Optimum Zone}

To simulate the optimum conditions for the diesel fuel desulfurization, the "mathematical model" given in Equation (4) can be applied. To attain such a target, the "method of iso-response curves" may be a means. Definitely, equation (4) is adapted to another arrangement, equation (5). As key parameters $X_{i}$ and $X_{j}$ were nominated, the other variables were arranged at their optimum levels. As a first step, the most effective factor, that is, the parameter that can highly influence the desulfurization yield $\left(\mathrm{X}_{1}\right.$ and $\left.\mathrm{X}_{3}\right)$ was nominated.

Then, those factors were fixed at their optimum levels, so X2 turns into the "key variable."

$$
X_{j}=\frac{a+b \cdot X_{i}+Y}{c+d \cdot X_{i}}
$$

The $\mathrm{X}_{\mathrm{i}}=\mathrm{f}\left(\mathrm{X}_{\mathrm{j}}\right)$ curves were charted for each constant yield $(\mathrm{Y})$, where Table 3 highlighted that tests 2, 6, and 7 gave a desulfurization yield more than $78 \%$. These "experimental conditions" were utilized in the current work of "iso-response yield curves," and the other two situations, which were highlighted previously, were studied as below.

Figure 5 shows that increasing $\mathrm{X}_{1}$ increases desulfurization yield when reaction time is low, but when increasing reaction duration, it is possible to achieve a percent of 79 . Figure 6 indicates that one cannot go beyond $79 \%$ sulfur elimination at $110 \mathrm{~s}$ and $9 \mathrm{v} . \%$ of IL the conditions of the test no. 7 when $\mathrm{X}_{1}$ is maintained at its low level (-1). That can be explained by the effect of the interaction $\mathrm{X}_{1} * \mathrm{X}_{3}$ as shown in Figure 3. When $\mathrm{X}_{2}$ is maintained at its high level as shown in Figure 5, it can be seen that the parameters $X_{1}$ and $X_{3}$ rise together with the desulfurization yield until reaching a desulfurization yield of $79 \%$ for a volume ratio (IL/oil) of $11 \%$ (test no. 6). For the same volume ratio at a minimal time reaction $70 \mathrm{~s}$, we can reach a desulfurization yield higher than $81 \%$ (test no. 2).

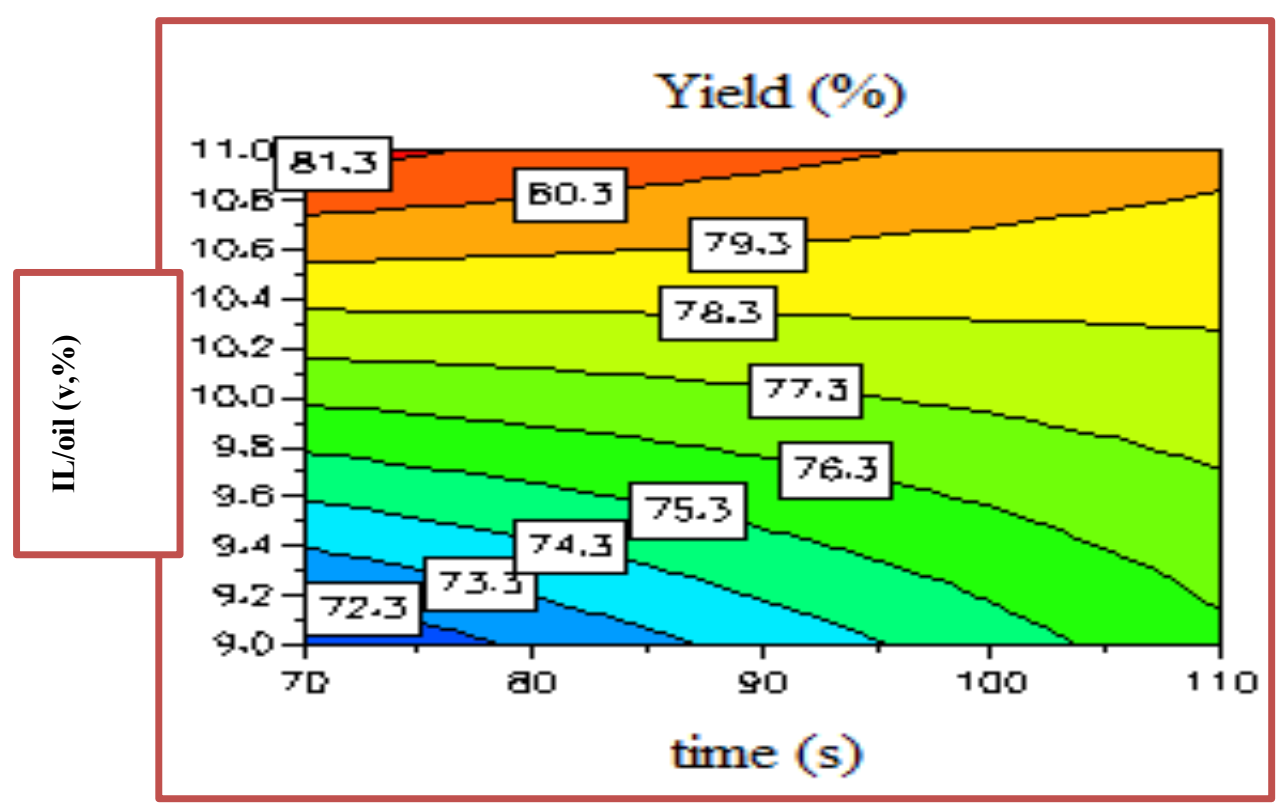

Figure 5. Evolution of (v, \%) (IL/oil) according to time reaction. 
After determining the theoretical optimal conditions, we performed experiments with these conditions and found an experimental optimal yield of 81.13 . The correlation is $99.21 \%$, which is shown in table 5 .

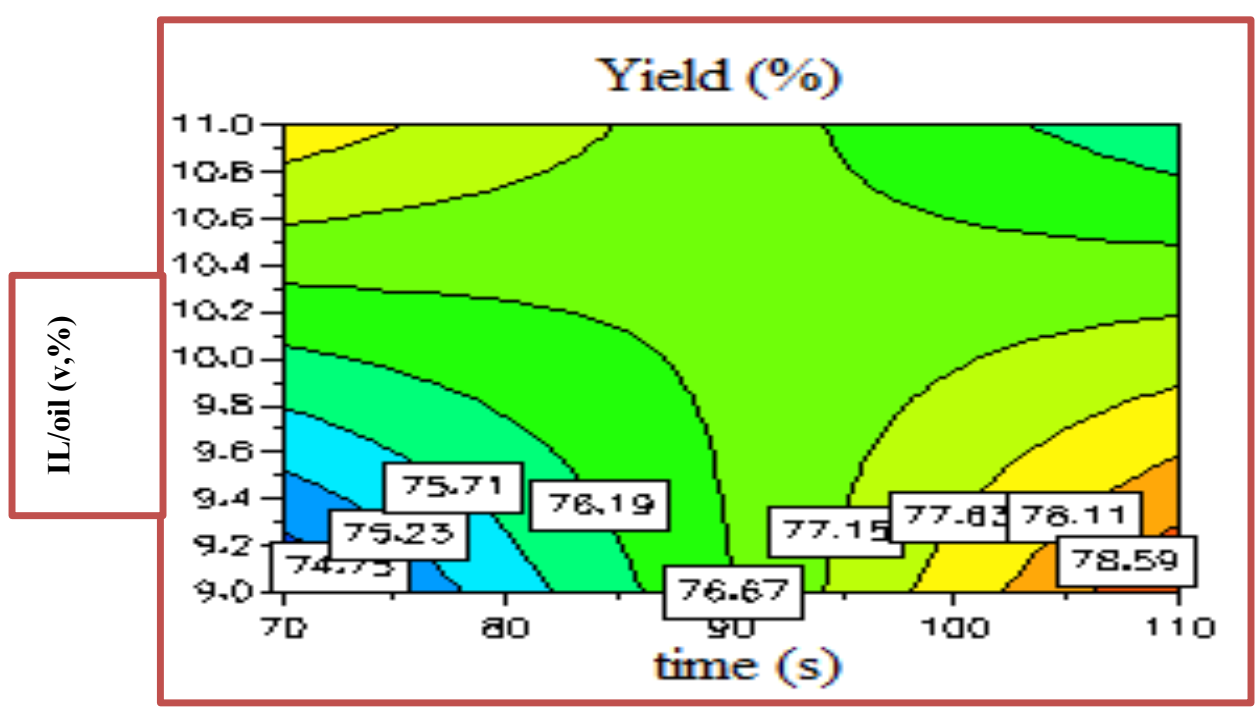

Figure 6. Evolution of (v, \%) (IL/oil) according to $\mathrm{X}_{2}=-1$, time reaction $\mathrm{X}_{2}=+1$.

Table 5. Optimal conditions for MAEOD.

\begin{tabular}{|c|c|c|c|c|}
\hline \multicolumn{3}{|c|}{ Optimal condition } & \multicolumn{2}{c|}{ Optimal yield } \\
\hline $\mathrm{X}_{1}$ & $\mathrm{X}_{2}$ & $\mathrm{X}_{3}$ & $\mathrm{R}_{\exp }(\%)$ & $\mathrm{R}_{\text {the }}(\%)$ \\
\hline 11 & 0.4 & 70 & 81.77 & 81.13 \\
\hline
\end{tabular}

\section{CONCLUSION}

A model that shows the effect of all investigated factors as well as their interactions has been established based on the experimental outcome with respect to the "full factorial design."

Based on the variance analysis, the statistical experiments not only allow identifying further data on the "simplified model," but also validate their strength. The circumstances of the microwaves assisted extraction/oxidation desulfurization have been experimented. The "experimental design" has been operated to go into the details a "regression model" for the process parameters analysis by spotting the influential parameters. The optimum yield $(81.77 \%)$ was achieved during a time radiation of $70 \mathrm{~s}$, with a catalyst/oil ratio of $0.4 \%$ and IL/oil volume ratio of $11 \%$; nonetheless, the results that were obtained using "iso-response curves" demonstrate that the analyses were carried out with $81.33 \%$ "confidence level." The interaction consequences among the parameters should be taken into concern. Using "full factorial experiment" application, the simulation and determination the optimal conditions are possible. 


\section{ACKNOWLEDGMENT}

The authors would like to thank the University of M'hamed Bougara Boumerdes and the University of Mosul for the facilities provided for the present research study.

\section{REFERENCES}

Abdullah, S. B., Aziz, H. A., \& Man, Z. 2018. Ionic liquids for desulphurization: a review. In Recent Advances in Ionic Liquids. IntechOpen.

Afzal, A., Kareemullah, M., \& RK, A. R. 2018. Production of biodiesel from various sources and comparative engine performance studies by using different biodiesel blends. Journal of Engineering Research, 6(4).

Aguiar, A., Ribeiro, S., Silva, A. M., Cunha-Silva, L., de Castro, B., Silva, A. M., \& Balula, S. S. 2014. An efficient eco-sustainable oxidative desulfurization process using $\mu$-oxo-bridged Fe (III) complex of mesotetrakis (pentafluorophenyl) porphyrin. Applied Catalysis A: General, 478: 267-274.

Atikler, U., Demir, H., Tokatlı, F., Tıhmınlığlu, F., Balköse, D., \& Ülkü, S. 2006. Optimisation of the effect of colemanite as a new synergistic agent in an intumescent system. Polymer degradation and stability, 91(7): 1563-1570.

Boehm, H. P. 1994. Some aspects of the surface chemistry of carbon blacks and other carbons. carbon, 32(5): 759-769.

Daabo, A. M., Hammo, K. E., Mohammed, O. A., Hassan, A. A., \& Lattimore, T. 2020. Performance investigation and design optimization of micro scale compressed air axial turbine for domestic solar powered Brayton cycle. Sustainable Energy Technologies and Assessments, 37: 100583.

Daabo, A. M. A. 2018. Stress analysis and aerodynamic optimization of small-scale compressed air turbines (Doctoral dissertation, University of Birmingham).

Daabo, A. M., Al-Mola, Y. S., Al-Rawy, A. Y., \& Lattimore, T. 2019. State of the art single-objective optimization of small scale cylindrical cavity receiver. Sustainable Energy Technologies and Assessments, 35: 278-290.

Gekhman, A. E., Stolarov, I. P., Moiseeva, N. I., Rubaijlo, V. L., Vargaftik, M. N., \&

Goupy, J., \& Creighton, L. 2006. Introduction to Experiments Plans. Ed Dunod, Paris.

Gürses, A., Yalçin, M., \& Doğar, C. 2002. Electrocoagulation of some reactive dyes: a statistical investigation of some electrochemical variables. Waste management, 22(5): 491-499.

Jiang, W., Zhu, W., Li, H., Chao, Y., Xun, S., Chang, Y., ... \& Zhao, Z. 2014. Mechanism and optimization for oxidative desulfurization of fuels catalyzed by Fenton-like catalysts in hydrophobic ionic liquid. Journal of Molecular Catalysis A: Chemical, 382: 8-14.

Lü, H., Deng, C., Ren, W., \& Yang, X. 2014. Oxidative desulfurization of model diesel using [(C4H9) 4N] 6Mo7O24 as a catalyst in ionic liquids. Fuel processing technology, 119: 87-91.

Ma, C., Dai, B., Liu, P., Zhou, N., Shi, A., Ban, L., \& Chen, H. 2014. Deep oxidative desulfurization of model fuel using ozone generated by dielectric barrier discharge plasma combined with ionic liquid extraction. Journal of Industrial and Engineering Chemistry, 20(5): 2769-2774.

Martinez-Magadan, J. M., Oviedo-Roa, R., Garcia, P., \& Martinez-Palou, R. 2012. DFT study of the interaction between ethanethiol and Fe-containing ionic liquids for desulfuration of natural gasoline. Fuel processing technology, 97: 24-29. 
Meman, N. M., Zarenezhad, B., Rashidi, A., Hajjar, Z., \& Esmaeili, E. 2015. Application of palladium supported on functionalized MWNTs for oxidative desulfurization of naphtha. Journal of Industrial and Engineering Chemistry, 22: 179-184.

Moiseev, I. I. 1998. Oxidations in the $\mathrm{H} 2 \mathrm{O} 2 \mathrm{VvAcOH}$ system. Evidence of vanadium (V) complexes with superoxide anion and singlet dioxygen molecule as ligands. Inorganica chimica acta, 275: 453-461.

Montgomery, D. C. 2001. Design and Analysis of Experiments, fifth ed. John Wiley \& Sons, New York.

Moussa, R., \& Alzeibak, A. F. 2014. Missions of ethanol fueled engine and carcinogenic gases. Journal of Engineering Research, 4(2), 1-17.

Mota, A., Butenko, N., Hallett, J. P., \& Correia, I. 2012. Application of VIVO (acac) 2 type complexes in the desulfurization of fuels with ionic liquids. Catalysis Today, 196(1), 119-125.

Nie, Y., Dong, Y., Bai, L., Dong, H., \& Zhang, X. 2013. Fast oxidative desulfurization of fuel oil using dialkylpyridinium tetrachloroferrates ionic liquids. Fuel, 103: 997-1002.

Su, W., Xing, Y., Ma, H., Li, R., Song, C., \& Tong, Z. (2019). Numerical simulation of a new horizontal spray tower for sintering flue gas desulfurization. Journal of Engineering Research, 7(4).

Woolins, J. D. 2010. Inorganic Experiments, WILEY-VCH Verlag, 141.

Zhang, Y., Xu, H., Jia, M., Liu, Z., \& Qu, D. 2018. Optimization of deep oxidative desulfurization process using ionic liquid and potassium monopersulfate. Journal of Chemistry.

Zhu, W., Li, H., Gu, Q., Wu, P., Zhu, G., Yan, Y., \& Chen, G. 2011. Kinetics and mechanism for oxidative desulfurization of fuels catalyzed by peroxo-molybdenum amino acid complexes in water-immiscible ionic liquids. Journal of Molecular Catalysis A: Chemical, 336(1-2): 16-22.

Zolotareva, D., Zazybin, A., Rafikova, K., Dembitsky, V. M., Dauletbakov, A., \& Yu, V. 2019. Ionic liquids assisted desulfurization and denitrogenation of fuels. Vietnam Journal of Chemistry, 57(2), 133-163. DOI: $10.1002 /$ vjch. 201900008 